\title{
KOJÈVE, LACAN E A FORMAÇÃ̃ DO EU
}

\author{
Anderson Aparecido Lima da Silva ${ }^{1}$ \\ Instituto Federal de São Paulo (IFSP) \\ https://orcid.org/0000-0001-8394-5525 \\ E-mail: anderson.usp@outlook.com
}

\section{RESUMO:}

Tomando como base interpretativa a Fenomenologia do espírito, de Hegel, Alexandre Kojève empreende uma teoria da "antropogênese" que aloca a constituição da consciência de si num campo marcadamente histórico e social, centrada notadamente na "dialética do senhor e do escravo". Mais do que isso, esta emerge numa esfera tomada pela conflitualidade própria ao operador central da socialização, o desejo, que é sempre, em último caso, desejo de reconhecimento. Atento a esta leitura, na senda do desenvolvimento de sua teoria do imaginário, Lacan lançava-se no encalço da necessidade de realocar certos pontos da teoria freudiana da constituição do Eu, visando contornar o suposto "biologismo" de Freud (presente, sobretudo, em sua teoria da "pulsão de morte") ao destacar a dependência fundamental da instância do outro no processo de "hominização", no qual a "agressividade" ocupa um papel inerente. Se os projetos de Kojève e Lacan apresentam inegáveis convergências, cumpre, no entanto, melhor compreendê-las, bem como estabelecer a singularidade de seus distanciamentos, inflexões e objetivos.

PALAVRAS-CHAVE: Hegel; Kojève; Lacan; Desejo; Imaginário; Estádio do espelho.

\section{KOJÈVE, LACAN AND THE EGO-FORMATION}

\begin{abstract}
:
Based on Hegel's Phenomenology of Spirit, Alexandre Kojève produces a theory of an "anthropogenesis" that allocates the constitution of self-consciousness in a markedly historical and social field centered on the "dialectic of the master and the slave". More than this, it emerges in a domaine seized by the conflictuality of such a central operator of socialization, namely the desire, which is always, in the last case, a desire for recognition. Aware of this idea and on the path of the development of an imaginary's theory, Lacan was pursuing the necessity to reallocate certain points of the Freudian constitution's theory of the ego. He was aiming to bypass Freud's supposed "biologism" (especially in his theory of the "death drive") by emphasizing the fundamental dependence of the other's figure on the process of "hominization", in which "aggressiveness" plays an inherent role. If the projects of Kojève and Lacan present undeniable convergences, it is necessary, however, to better understand them, as well as to establish the uniqueness of their distances, inflections and objectives.
\end{abstract}

KEYWORDS: Hegel; Kojève; Lacan; Desire; Imaginary; Mirror Stage.

Sabe-se que Alexandre Kojève não foi apenas responsável pela reintrodução do pensamento de matiz hegeliano na França, mas, como bem notou Vincent Descombes (1979), colocou também

${ }^{1}$ Doutor(a) em Filosofia pela Universidade de São Paulo (USP), São Paulo - SP, Brasil. Professor(a) do Instituto Federal de São Paulo (IFSP), Jacareí - SP, Brasil.

SILVA, Anderson Aparecido Lima da. Kojève, Lacan e a formação do eu. Griot : Revista de Filosofia, Amargosa - BA, v.22 n.1, p.6884, fevereiro, 2022. 
um certo Hegel na "vanguarda" dos "ciclos mais avançados" do pensamento francês. Não seria exagero afirmar que o Seminário sobre a Fenomenologia do espírito animado por Kojève de 1933 a 1939 na École Pratique des Hautes Études de Paris viria a se tornar um dos episódios mais significativos da cultura francesa dos anos 1930. Dentre seus ouvintes figuravam nomes que se notabilizariam sobretudo no pós-guerra, tais como Maurice Merleau-Ponty, Raymond Queneau, Georges Bataille, Pierre Klossowski, Jean Hyppolite, Raymond Aron, Éric Weil, eventualmente André Breton, indiretamente Jean-Paul Sartre. Além, é claro, do Dr. Jacques Lacan (AUFFRET, 1990, pp. 253-256).

O reconhecido talento narrativo de Kojève colocava na ordem do dia uma leitura de Hegel que vinha ao encontro das ansiosas expectativas de uma orientation vers le concret, o que por si só compreendia tanto a implosão do malfadado "neo-kantismo" acadêmico como também de certa linha bergsonista da "vida interior". Quadro que Sartre buscou resumir na expressão de uma "filosofia alimentar", qual seja, um "Espírito-Aranha [que] atraia as coisas para a sua teia, cobria-as com uma baba branca e lentamente as deglutia, reduzindo-as à sua própria substância" (SARTRE, 2005, p. 55). "Espírito-Aranha" que, sob a insígnia da "representação" ou da "vida interior", tomava a forma de um dado "substancialismo psicologista", reverso simétrico do "ingênuo" e questionável "objetivismo" ou "mecanicismo", já há algum tempo intensamente criticados também por Politizer (2003), outro ícone desse "dramático" período.

Muito já se discutiu a notória "criatividade" dessa leitura que, embora tenha resoluções perspicazes, nem sempre é um modelo de leitura rigorosa de Hegel (ARANTES, 2021). Algo que o próprio Kojève não fazia questão de omitir, conforme afirma em carta a Tran-Duc-Thao datada de 7 de outubro de 1948: "minha obra não tinha os caracteres de um estudo histórico; importava-me relativamente pouco saber o que Hegel mesmo disse em seu livro" (JARCZYK; LABARRIÈRE, 1996, p. 94)2. Mais do que isso, a ênfase direcionada à "dialética do senhor e do escravo" nos seminários do filósofo russo tinha como objetivo não só "esquematizar o conteúdo da fenomenologia", mas também lançar "essencialmente uma obra de propaganda destinada a arrebatar [frapper] os espíritos". E para tanto, ao fim e ao termo, "eu, diz Kojève, fiz um curso de antropologia fenomenológica me servindo de textos hegelianos" (JARCZYK; LABARRIÈRE, 1996, p. 94).

Ora, mas o que realmente vem colocar em jogo essa "antropologia fenomenológica" de Kojève? Em primeiro lugar, ela teria a vantagem de pensar o sujeito humano em sua "totalidade concreta", compreendendo por isso a "síntese" de fatos psíquicos e sociais. Em segundo lugar, essa "antropologia fenomenológica" trata da constituição do sujeito utilizando-se de uma teoria da "antropogênese" de feitio histórico e social. Nessa direção, Kojève alocava a constituição da consciência de si num terreno marcadamente habitado pela conflituosidade implicada no operador central da socialização chamado desejo, que é sempre, no fundo, um desejo de reconhecimento.

Não é de admirar que tal projeto tenha atraído tantos membros da inteligentzia francesa e, notoriamente, Lacan, uma vez que vinha, desde a publicação de sua tese de doutoramento em 1932 (Da Psicose paranóica em suas relações com a personalidade), no encalço da necessidade de realocar certos pontos da teoria freudiana da constituição do ego. Sua pesquisa já apontava desde então à dependência fundamental da figura do outro na constituição do eu, colocando assim a questão do sujeito na interconexão entre o subjetivo e o objetivo, isto é, na realidade social. Afinal, não poderia ser diferente para alguém que buscava "uma análise psicológica concreta, que se aplica a todo

2 Todas as traduções, salvo indicação em contrário, são de minha autoria.

SILVA, Anderson Aparecido Lima da. Kojève, Lacan e a formação do eu. Griot : Revista de Filosofia, Amargosa - BA, v.22 n.1, p..6884, fevereiro, 2022. 
desenvolvimento da personalidade do sujeito, isto é, aos acontecimentos de sua história, aos progressos da sua consciência, a suas reações no meio social" (LACAN, 1987, p. 354). Meio social que, por sua vez, "desempenha no desenvolvimento do animal-homem um papel primordial", adquirindo seu real estatuto quando considerado o papel do desejo na constituição de uma "realidade humana" dependente de identificações essencialmente "agressivas"3. A convergência de projetos é inegável. Contudo, especifiquemos melhor a proposta kojèveana a fim de, em seguida, melhor compreender alguns aspectos da leitura empreendida por Lacan.

\section{Kojève: uma antropogênese social e histórica}

Um dos pontos de partida da argumentação de Kojève ${ }^{4}$ destaca que a origem do sujeito, dada no interior de uma realidade biológica, é a negação de sua condição natural: o homem solitário que apenas contempla o objeto em sua quietude é "absorvido" por esta contemplação e é tanto menos consciente de si quanto mais está imerso no objeto conhecido. Neste registro, tal como o animal, encontra-se reduzido apenas a um "sentimento de si". Ora, mas o que poderia impelir o "homem absorvido pelo objeto" a "voltar a si"? Resposta de Kojève: o homem "só pode voltar a si por um desejo", é apenas por via do desejo que o homem pode dizer "Eu": é "como seu desejo que o homem se constitui e se revela" (KOJÈVE, 2002, p. 11).

Mas qual seria exatamente o estatuto do desejo? O que o autor nos informa é que, antes de mais nada, "o desejo considerado como desejo, isto é, antes de sua satisfação, é apenas um nada revelado, um vazio irreal" e, na medida em que é constituído enquanto desejo, divisamos o estatuto eminentemente negativo do homem ou do sujeito: um "Eu" "radicalmente oposto" à positividade do “não-Eu” (KOJÈVE, 2002, p. 12). A “inquietude" característica do desejo leva o homem à ação, a qual, dada a negatividade primordial desse desejo, só pode se configurar enquanto ação negadora. Algo diferente de uma aniquilação pura e simples por se tratar de uma Aufhebung que, ao negar, fazse também criação e manutenção de outra realidade, demonstrando que a ação negadora tem, na verdade, como princípio transformar algo em outra coisa: por exemplo, quando come determinado objeto, isto é, quando o nega, o homem "cria e mantém sua própria realidade pela supressão da realidade diferente da sua, pela transformação de uma realidade outra na sua" (KOJÈVE, 2002, p. $12)$.

Na ação negadora do desejo está, por conseguinte, implicada tanto a alteridade negada quanto uma transformação do objeto que é também uma transformação no ser - no caso, o homem - que o nega. Poderíamos mesmo falar de uma espécie de "transcendência negativa" caracterizadora do desejo na medida em que, para se posicionar, para se afirmar em sua determinidade, o sujeito tem de transcender todo objeto, ato pelo qual, por sua vez, implicado sempre nas malhas do devir temporal, implica na transformação ou na "transcendência" de si mesmo. Dito de outro modo, "a compreensão

\footnotetext{
3 Note-se que, no caso de Aimée - analisado por Lacan em sua tese -, há uma identificação logo transformada em agressividade: "mulheres de letras, atrizes, mulheres do mundo, elas representam a imagem que Aimée concebe da mulher que, em algum grau, goza da liberdade e do poder social. Mas aí explode a identidade imaginária dos temas de grandeza e dos temas de perseguição: este tipo de mulher é exatamente o que ela própria sonha se tornar. A mesma imagem que representa seu ideal é também o objeto de seu ódio" (Lacan, 1987, p. 354).

${ }_{4}^{4}$ As lições de Kojève foram fragmentariamente reunidas por Raymond Queneau apenas em 1947, sob o título de Introduction à la lecture de Hegel: leçons sur la Phénoménologie de l'esprit, proféssées de 1933 à 1939 à l'École des Hautes Études, réunis et publiées par Raymond Queneau.
}

SILVA, Anderson Aparecido Lima da. Kojève, Lacan e a formação do eu. Griot : Revista de Filosofia, Amargosa - BA, v.22 n.1, p..6884, fevereiro, 2022. 
do desejo como ser do sujeito impede que o homem seja pensado enquanto Ser que é eternamente idêntico a si mesmo. O homem deve ser pensado como um nada, um vazio, ação negadora que nadifica o Ser para transformá-lo e, neste movimento, se transformar" (SAFATLE, 1997, p. 49).

Todavia, se mantido nesta esfera, o desejo humano não se distinguiria suficientemente de seu correlato animal. Para se afirmar como desejo propriamente humano é preciso que esse desejo se enderece a algo diferente do objeto natural, caso contrário será apenas um "eu-coisa", um "Eunatural". Para que o sujeito atinja realmente seu estatuto de sujeito ou, o que não parece ser muito diferente em Kojève, para que o sujeito atinja a "consciência-de-si", é preciso algo mais: "ora, a única coisa que ultrapassa o real dado é o próprio desejo" (KOJÈVE, 2002, p. 12).

A conclusão não poderia ser outra: o desejo propriamente humano tem por objeto um outro desejo. Ao contrário do animal, que se satisfaz com a coisa natural, o homem só poderá encontrar satisfação em um não-Ser, isto é, em outro desejo. O Homem não deseja esta ou aquela coisa, em última análise; não deseja nem mesmo uma coisa, seja ela qual for, mas um desejo. Posto isso, cumpre observar que a "condição necessária" para que se constitua realmente um desejo humano é que haja primeiro uma "pluralidade de desejos", ainda que na forma da multiplicidade de "rebanho" (desejos "animais"), acrescenta Kojève, "por isso a realidade humana só pode ser social" (KOJÈVE, 2002, p. $13)$.

Contudo, para que esse rebanho passe a ser uma sociedade, isto é, se humanize, é preciso que seus membros encontrem no desejo do outro o objeto de seu próprio desejo. Levado à radicalidade de suas consequências, o desejo que busca até mesmo um objeto natural somente é humano "na medida em que é mediatizado pelo desejo de outrem dirigido ao mesmo objeto", isto é, o que se deseja no objeto não é exatamente o desejo do objeto per se, mas o(s) desejo(s) "intencionado(s)" a tal objeto. Assim, assinala Kojève (2002, p. 13), “um objeto perfeitamente inútil do ponto de vista biológico (como uma condecoração ou a bandeira do inimigo) pode ser desejado porque é objeto de outros desejos". Portanto, no caso humano, não se deseja objetos, apenas desejos. Daí porque "a história humana é a história dos desejos desejados".

Esboçado esse itinerário de Kojève, afiguram-se enfim as condições da antropogênese: se a realidade humana é uma realidade social, a sociedade só é humana como conjunto de desejos desejando-se mutuamente como desejos. O desejo humano, ou melhor, antropogênico (que "constitui um indivíduo livre e histórico consciente de sua individualidade, de sua liberdade, de sua história e, enfim, de sua historicidade"), difere, desta feita, do desejo animal (que constitui um Ser natural, apenas vivo e tendo apenas o sentimento de sua vida) pelo fato de buscar não um objeto real, "positivo", dado, mas um outro desejo (KOJÈVE, 2002, p. 13).

Contudo, cabe ainda colocar uma questão que acarretará um importante desenlace:

se todo desejo é 'desejo de um valor' (Kojève) e se o valor que guia o desejo humano [na medida em que é humano] não pode ser a vida animal, qual seria então? Em outras palavras, como deve funcionar o 'desejo antropogênico' para ser, ao mesmo tempo, negação do valor vital e desejo de outro desejo? É para responder a essa dupla pergunta que surge o tema da luta das consciências" (SIMANKE, 2002, p. 417).

Nas palavras de Kojève (2002, p. 14),

"desejar um desejo é por-se no lugar do valor desejado por esse desejo", ou ainda, "desejar o desejo do outro é, em última análise, desejar o valor que eu sou ou que represento seja o valor

SILVA, Anderson Aparecido Lima da. Kojève, Lacan e a formação do eu. Griot : Revista de Filosofia, Amargosa - BA, v.22 n.1, p..6884, fevereiro, 2022. 
desejado por esse outro: quero que ele reconheça meu valor como seu valor, quero que me reconheça como um valor autônomo. Isto é, todo desejo humano, antropogênico, gerador da consciência-de-si é, pois, função do desejo de reconhecimento".

Esse desejo de reconhecimento, por sua vez, só pode se resolver numa luta, chamada por Kojève de "puro prestígio"5. Desejo, alteridade, reconhecimento se encontram, pois, na base da rivalidade humana que leva à "luta por reconhecimento" ou por "puro prestígio".

Destarte, para que haja reconhecimento é preciso como condição lógica que os dois combatentes se mantenham vivos, assumindo, entretanto, posturas diferentes: um reconhece, é o escravo; outro é reconhecido, é o senhor. Nas palavras de Kojève (2002, p. 15), um deles deve "abandonar seu desejo e satisfazer o desejo do outro: deve reconhecê-lo sem ser por ele reconhecido. Ora, reconhecê-lo assim é reconhecê-lo como senhor e reconhecer-se (e fazer-se reconhecer) como escravo do senhor". A servidão do escravo, posta nestes termos, deve ser compreendida como a "alienação" de si em relação a outrem, o senhor. Engendra-se, desse modo, na trilha da "constituição" do sujeito, uma relação conflituosa, hierárquica e assimétrica entre indivíduos na e pela qual o desejo aparece como operador central da "hominização" que, por sua constituição mesma, pode eclodir somente envolvida nessa teia do reconhecimento. E na medida em que aquilo que nos interessará mais de perto em nossa discussão são as condições de possibilidade desta "antropogênese" e sua estreita ligação com a "luta por reconhecimento" que a implica, não nos deteremos em sua "resolução" - o que ressaltaria o lugar do "trabalho" nessa contextura. Com Kojève, por ora, ficamos por aqui.

\section{Lacan: do sujeito orgânico ao sócio-cultural}

Passando a Lacan, podemos começar por afirmar que, se desde sua tese a questão da gênese do sujeito estava na ordem do dia, ao elaborar sua teoria do imaginário suas preocupações antropológicas serão ainda mais visíveis. No entanto, se sua tese ressaltava a dimensão eminentemente social da realidade humana na constituição da personalidade, esse caráter social, não obstante, vinha se acrescentar a um conjunto de determinações próprias ao reino dos seres vivos em geral. Já com o desenvolvimento da teoria do imaginário, "o ser humano não é apenas, por essência, um ser social, mas é um ser social na medida em que não é outra coisa" (OLGIVIE, 1991, p. 92). A perspectiva da tese de contornar o "reducionismo objetivista" centrando o determinismo próprio à causalidade psíquica na inversão da causalidade orgânica pela social será, assim, radicalizada. Não é por outro motivo que Lacan tanto se esforçará na empresa de um remanejamento teórico que seja capaz de dar a devida importância ao lugar ocupado pela relação social em seu papel constituinte e formador do Eu. Uma teoria, portanto, duplamente antropológica é o que Lacan propõe, duplamente conquanto implica não só uma "antropogênese", isto é, a origem do sujeito em sua especificidade "ontológica", mas também o fato de que concebe essa gênese numa situação social. É notório, desta feita, o interesse que a leitura proposta por Kojève poderia suscitar no jovem psicanalista.

Como resultado dessa radicalização antropológica - como se pode observar em "Os complexos familiares na formação do indivíduo" (1936) -, Lacan não cessará de insistir que, na espécie humana,

\footnotetext{
5 Conforme afirma Kojève, "o termo 'luta por puro prestígio' não se encontra efetivamente em Hegel, mas eu acredito que se trata unicamente de uma diferença de terminologia, pois tudo isso que eu digo ao sujeito dessa luta se aplica perfeitamente a isso que Hegel chama "luta pelo reconhecimento" (JARCZYK; LABARRIËRE, 1996, p. 64).
} 
"as instâncias culturais dominam as naturais" (LACAN, 2003, p. 30), ou ainda, num texto do mesmo ano - "Para além do princípio de realidade" -, que "a "natureza" do homem é sua relação com o homem" (LACAN, 1998a, p. 91). No miolo dessas afirmações, é mister notar que o objetivo de Lacan parece ser o de destituir os fatores biológicos de eficácia explicativa, ou melhor, "substituir os determinantes biológicos por outros, de feitio antropológico" (SIMANKE, 2002, p. 273). O que se anuncia neste projeto é a "subversão cada vez mais vasta da natureza que é a hominização do planeta" (LACAN, 1998a, p. 91). Do natural ao cultural, mais uma vez, a lição é repetida: "a realidade humana só pode ser social" (KOJÈVE, 2002, p. 13), isto é, em última instância, uma "negação" da condição biológica ou "natural".

O reverso desse posicionamento nos permite compreender as críticas que Lacan endereça a determinados aspectos da metapsicologia freudiana, sobretudo no que diz respeito ao que considera o "tão inadequado quanto estéril" "conceito de instinto", no seio do qual o jovem psiquiatra encontra o reduto de um certo "substancialismo" ou mesmo "objetivismo", refém, por sua vez, de uma função biológica como seu substrato. Ao contrário do que propõe o "preconceito do biólogo", a psicologia concreta defende que a ordem humana se diferencia basicamente da ordem animal à medida que se instaura em sua constituição uma "mediatização cultural", diferenciando-se do "imediatismo" animal, ou do puro "instinto". Ainda, em outras palavras, enquanto no mundo animal são os instintos que governam as condutas em relação aos objetos, no mundo humano há a "subversão de qualquer fixidez instintiva" (LACAN, 2003, p. 34), o que se traduz na assertiva de que é em certa estrutura de relações sociais, a cultura propriamente dita, que encontramos seu determinante primordial. Assim, para além do instinto, Lacan propõe a elaboração de um "conceito mais concreto e mais fecundo introduzido no estudo do comportamento humano" (LACAN, 2003, p. 34), a este conceito o psicanalista dá o nome de "complexo". É através do conceito de "complexo" que o autor poderá propor uma "inversão teórica" por meio da qual não isola ou nega o conceito de instinto, mas o "esclarece" 6 .

Nesse ínterim, cumpre afinal arguir: que é o complexo? Ressaltemos, por ora, apenas sua característica capital: "o que define o complexo é que ele reproduz uma certa realidade do ambiente" (LACAN, 2003, p. 33). Ora, visto que o que está em jogo é "uma certa realidade do ambiente", Lacan não oscilará em conciliar este aspecto àquela que, até aqui, é a experiência social que sustenta os "processos fundamentais do desenvolvimento psíquico", ou ainda, o grupo humano que desempenha "papel primordial na transmissão da cultura", qual seja, a família. À medida que coloca em cena termos como "fundamento", "desenvolvimento", "transmissão", Lacan encaminha-se ao epicentro de suas reflexões, conduzindo àquele que se tornará o núcleo dos desenvolvimentos sobre o imaginário, a saber, a questão da constituição do eu, ou ainda, da origem do eu na medida em que sua "natureza" particular é a de ser social por excelência.

A alternativa que permite a Lacan centrar as apostas na perspectiva sócio-cultural em contraponto à perspectiva "orgânica" apoia-se num ponto basal: a "falta original" que caracterizaria o sujeito na tradução da dita "impotência vital" dos primeiros meses de vida que particulariza o

\footnotetext{
6 "Embora o complexo em seu exercício pleno seja da alçada da cultura, e embora essa seja uma consideração essencial para quem quer explicar fatos psíquicos da família humana, isso não equivale a dizer que não exista relação entre o complexo e o instinto. Mas, fato curioso, em razão das obscuridades opostas à crítica da biologia contemporânea pelo conceito de instinto, o conceito de complexo, apesar de introduzido recentemente, revela-se mais bem adaptado a objetos mais ricos; é por isso que repudiando o apoio que o inventor do complexo julgava dever procurar no conceito clássico de instinto, acreditamos que, por uma inversão teórica, é o instinto que poderíamos esclarecer atualmente por sua referência ao complexo" (LACAN, 2003, p. 34).
} 
homem como "um animal de nascimento prematuro". A falta de coordenação e o inacabamento anatômico desses primeiros tempos assinalariam uma espécie de "fetalização" do homem mesmo após seu nascimento. Vale notar que se a afinidade com Kojève é mais do que clara na elaboração dessa "falta original" que caracteriza a negatividade constitutiva do sujeito, todavia Lacan procura o esteio de fundamentação para tal passagem na biologia, mais especificamente em Louis Bolk, que em seu livro Das problem der Menschewerdung (1926), defende a fetalização do sistema nervoso. Tudo se passa como se Lacan buscasse um lastro de segurança científica ancorado à biologia para fundamentar a já referida "falta original", o que o privaria de entrar numa infindável discussão "metafísica".

Mas o que se ganharia partindo desse arranjo? Em primeiro lugar, a indicação de que o indivíduo padece de um vazio orgânico originário abre a possibilidade de que que o "social" venha ocupar o lugar dessa carência inicial. Aliás, Lacan é o primeiro a ressaltar que se trata de "uma deficiência biológica positiva" (LACAN, 2003, p. 39), dando a entender que a determinação social do indivíduo humano é originária e super-compensatória frente ao animal, que só conta com o instinto. Em outras palavras, "a insuficiência vital originária faz com que o imaginário ocupe o lugar deixado vago pelo instinto e seja capaz de veicular, desta posição central que ocupa, uma série de determinantes sociais da conduta e do psiquismo em geral, que é, como sabemos, o objetivo declarado de Lacan" (SIMANKE, 2002, p. 314).

Em segundo lugar, a perspectiva da prematuração humana, a "deiscência do organismo", permite notar que não há, a princípio, uma autorreferência, ou ainda, funções de individualização e síntese da experiência, o que equivale a dizer que não há a priori um "eu", nem um "objeto". Indeterminação inicial cujo ponto nevrálgico revela que falta ao prematuro inclusive o reconhecimento do corpo próprio, que lhe permitiria a apreensão de seu corpo enquanto totalidade e a operação de distinções entre o interno e o externo, entre o eu e a alteridade.

Ora, ressaltada essa "falta original", Lacan sugere que a formação do eu dependerá fundamentalmente de um processo ligado à constituição da imagem do corpo próprio e de seu concomitante reconhecimento por esse eu primordial. Com esse passo, adentramos o cerne da proposta antropogênica do psicanalista francês. O território que divisamos é o do célebre "estádio do espelho", exposto mormente no texto "O estádio do espelho como formador da função do Eu [Je] tal como nos é revelada na experiência psicanalítica", de 1949. O estádio do espelho visará demostrar, antes de mais nada, como a formação ou constituição do eu depende essencialmente de um processo ligado à constituição da imagem do corpo próprio que, por sua vez, atuará como dispositivo fundamental tanto de individualização quanto de socialização.

\section{O estádio do espelho}

Antes de abordar diretamente o que seria o "estádio do espelho", Lacan se vê na necessidade de especificar de qual "eu" se trata, ou melhor, de qual eu não se trata de expor, algo que nos parece de suma importância para colocar o debate em seu verdadeiro plano: trata-se de se opor "a qualquer filosofia oriunda diretamente do Cogito" (Lacan, 1998b, p. 96). Como nos aponta tanto a dinâmica da discussão quanto o final do texto, o remetente dessa inamistosa missiva é Jean-Paul Sartre, em cuja filosofia Lacan parece identificar o arcabouço de uma filosofia da "autoidentidade" ou da 
imediaticidade da consciência sempre transparente a si mesma, que nutre ainda a "ilusão de autonomia" do eu, oriunda, por sua vez, das expectativas da modernidade cartesiana ${ }^{7}$.

Duas prioridades levam Lacan a se posicionar na contramão dessa via. Em primeiro lugar, desde o início a prerrogativa de Lacan é a de pensar em uma antropologia anti-individualista e calcada na primazia das determinações extraindividuais ou sociais; em segundo lugar, por se tratar de uma determinação em seu sentido forte, é preciso contestar a precedência do sujeito do conhecimento, ressaltando o desconhecimento que o acompanha através da constituição históricocultural de seu eu ${ }^{8}$. Assim, o que se desenvolverá no escrito que temos em foco aponta que o surgimento do eu não se confundirá com uma "tomada de consciência" ou de conhecimento mediante um reflexo adequado. Trata-se, portanto, de "algo que se trama no sujeito à sua revelia, e que ele não é convocado a reapreender", processo este que "não desemboca em qualquer "noção", qualquer progresso do conhecimento, nem qualquer maturação psicológica que permitisse ao sujeito unificar suas funções" (OLGIVIE, 1991, p. 107). Em suma, "o argumento implícito é qualquer coisa assim: é necessário reinventar um sujeito que, ao contrário do cartesiano, não seja autônomo e incondicionado, mas determinado e dependente; a ordem de determinação adequada ao sujeito é a ordem social, que pode ser reduzida a sua expressão mínima (o outro)" (SIMANKE, 2002, p. 403).

Dito isso, podemos nos direcionar mais diretamente ao "estádio do espelho" que, antes de qualquer coisa, reporta-se à observação do comportamento e da psicologia comparada. Inspirado nos estudos de Henri Wallon (Conscience et individualisation du corps propre - 1931), o núcleo da observação em questão parte da "flagrante diferença" do comportamento que a criança, a partir dos seis meses, apresenta diante de sua imagem no espelho em comparação ao chimpanzé: mesmo numa idade em que ainda "é superada em inteligência instrumental pelo chimpanzé", a criança "já reconhece não obstante como tal sua imagem no espelho" (LACAN, 1998b, p. 96). A prova de que de alguma maneira a criança "sabe", reconhece sua imagem enquanto tal é a de que, em vez de se desinteressar pela experiência - como o faz o chimpanzé -, o filhote humano, mesmo após notar essa “inanidade da imagem", ou seja, seu caráter representativo, dá ainda assim mostras de um interesse lúdico associado a sua imagem especular através da gesticulação sistemática e da expressão exultante do primeiro $A h$ ! de reconhecimento, que retrata, para Lacan, a "assunção triunfante da imagem com a mímica jubilatória que a acompanha" (LACAN, 1998c, p. 186), deixando entrever "o sentimento de compreensão em sua forma inefável" (LACAN, 2003, p. 47).

Mas qual é exatamente o sentido desse caráter jubilatório? Qual o teor desse "sentimento de compreensão"? Para responder a essas questões, é preciso atentar que tal deslumbramento ocorre num momento em que a criança é marcada pela já referida "impotência motora", isto é, pela discordância intraorgânica dos primeiros meses de vida. Não há, em princípio, uma autorreferência, pois falta ao prematuro o reconhecimento do corpo próprio que lhe permitira a distinção entre o interno e o externo, entre o eu e a alteridade. Ora, neste momento, ao "reconhecer" pela primeira vez sua imagem no espelho - ou, ainda, por meio do corpo de um "outro" ${ }^{\text {" }}$, a criança tem uma apreensão

\footnotetext{
${ }^{7}$ Ver, a este respeito, sobretudo o artigo “A liberdade cartesiana” (SARTRE, 2005, pp. 285-300).

${ }^{8}$ É mister observar neste ponto uma patente diferença entre Lacan e Kojève, pois se este via o sujeito como um "indivíduo livre e histórico consciente de sua individualidade, de sua liberdade, de sua história e, enfim, de sua historicidade" (KOJÈVE, 2002, p. 13), Lacan, na contracorrente do "indivíduo livre", vê no desconhecimento processual de sua constituição a determinação própria ao sujeito que permitiria o estabelecimento de uma cientificidade conveniente ao campo das "ciências humanas".

9 Lacan não descarta a hipótese de que a imagem do corpo próprio advenha também por introjeções de imagens do corpo de outra criança, fato que simplificaria a exposição em termos didáticos, mas que nada alteraria em termos estruturantes.
} 
total e unificada de seu próprio corpo. Nas palavras de Lacan (2003b, p. 96), "a só vista da forma total do corpo humano dá ao sujeito um domínio imaginário do seu corpo", gerando um efeito compensatório que, embora imaginário, dá ensejo ao processo mediante o qual “o [eu] se precipita numa forma primordial" (LACAN, 1998b, p. 97). Essa "precipitação" ${ }^{10}$ permite ao filhote de homem passar da "insuficiência" à "antecipação", ou seja, abandonar a anárquica e fragmentária descoordenação orgânica da negatividade inicial com vistas a uma unidade calcada na aquisição do corpo próprio, expressão por excelência do eu primordial. A imagem especular, nestes termos, é o gatilho de uma unidade primeira e a base do desenvolvimento posterior desse ser que se identifica e reconhece nessa imagem que lhe vem de fora.

Lacan organiza essa operação fundamental do "vir-a-ser" do Eu em torno da idéia de identificação: "basta compreender o estádio do espelho como uma identificação, no sentido pleno que a análise atribui a esse termo, ou seja, a transformação produzida no sujeito quando ele assume uma imagem" (LACAN, 1998b, p. 97). Ora, esse tipo de afirmação só é possível à medida que Lacan concebe a "transformação" proveniente da identificação pela imagem, qual seja, o surgimento do corpo próprio, como uma Gestalt, o que significa dizer que a identificação se dá através da apreensão e assimilação de uma forma que fornece um princípio global de organização da percepção e da conduta no que diz respeito à "forma total do corpo" adquirida pela criança.

Sendo assim, "a imagem forma. Ela não reproduz, mas configura. Ela faz entrar em uma forma, ela 'formata' ou conforma. Sua consistência própria e sua potência intrínseca de organização determinam uma circunscrição psíquica singular" (MARCOS, 2003, pp. 345-346), de tal modo que a apreensão imaginária do corpo próprio não é mera imitação ou representação. Ela é desencadeadora, indutora de uma mudança de caráter fundante e originário, que sintetiza a "matriz simbólica em que o [Eu] se precipita numa forma primordial" (LACAN, 1998b, p. 97). É por ser uma matriz e não uma fase do desenvolvimento entre outras destinada a ser superada - note-se, portanto, as precauções que se deve dedicar ao termo "estádio" - que o "estádio do espelho" tem valor de tipo ideal, de modelo para toda a seqüência de desenvolvimento posterior, ocupando assim importância fundamental no caráter formativo do Eu, posto que se configurará como aporte de todas as "identificações secundárias" que conduzirá ao sujeito propriamente dito. Essas identificações assumem um caráter crucial a tal ponto que Lacan poderá afirmar que "o Eu é um objeto feito como uma cebola, podemos descascá-lo e encontraremos as identificações sucessivas que o constituíram" (LACAN, 2003b, p. 194).

Esse modo de visar o Eu ressalta o seu caráter clivado, no qual a alteridade desempenha um papel constitutivo. Para retomarmos o fio argumentativo no que toca a esta "forma primordial" do eu, cumpre salientar que o eu-corpo próprio "precipita-se" como autorreferência à imagem de um outro vinda do exterior. Dito de outro modo, se o "estádio do espelho" é o momento do surgimento da primeira relação consigo, esta é, ao mesmo tempo, incondicionalmente, uma relação com o outro. $\mathrm{O}$ que implica dizer que, se a imagem é, por um lado, a operadora do processo de individualização, ela também é, concomitantemente, dispositivo central de socialização, conquanto a condição de possibilidade da aquisição da individualidade é sua confrontação com uma alteridade que lhe constitui. Disso segue-se que "o eu é referente ao outro. $O$ eu se constitui em relação ao outro. Ele é o

${ }^{10}$ Como bem nos lembra Olgivie (1991, p. 113), esse "precipitar-se" "deve ser entendido em seu sentido químico: um corpo que se deposita por precipitação quando nasce, sólido e insolúvel, numa fase líquida. O sujeito é um tal precipitado que não preexiste a si mesmo".

SILVA, Anderson Aparecido Lima da. Kojève, Lacan e a formação do eu. Griot : Revista de Filosofia, Amargosa - BA, v.22 n.1, p..6884, fevereiro, 2022. 
seu correlato. O nível no qual o outro é vivido situa exatamente o nível no qual, literalmente, o eu existe para o sujeito" (LACAN, 2003b, p. 63). Toda atividade subjetiva é, portanto, transpassada pela alteridade. Donde Lacan não veja "nenhuma dificuldade lógica" no emparelhamento de frases aparentemente tão díspares quanto a afirmação do índio bororo que profere "eu sou uma arara" daquela do cosmopolita que diz "eu sou médico": "Essas diversas fórmulas só são compreensíveis, no final das contas, em referência à verdade do 'Eu é um outro', menos fulgurante na intuição do poeta do que evidente aos olhos do psicanalista" (LACAN, 1998d, p. 120).

Afirmar que é de fora que vem o interno ou o Eu, é afirmar também que o indivíduo é sempre exterior a si: "o ser humano não vê sua forma realizada, total, a miragem de si mesmo, a não ser fora de si" (LACAN, 2003b, p. 164). Outro modo de dizer que, no limite, "não há nada de próprio na imagem do corpo" (SAFATLE, 2006, p. 77). Asseverar que não há nada de próprio na imagem do corpo ou que este pode ver-se somente fora de si é ressaltar que o Eu só pode se manifestar como instância de autorreferência através de sua dependência ao outro, o que infere, por sua vez, a "identidade alienante" de um ser que está sempre fora de si e que para ser si mesmo depende da alienação fundamental que constitui a imagem refletida de si mesmo. Dessa forma, a unidade originária da Gestalt apresenta suas fraturas assim que deslocamos o foco à alteridade que a constitui, dando azo, por sua vez, a uma "alienação original" do Eu. A Gestalt protagoniza, portanto, "por esses dois aspectos de seu surgimento, a permanência mental do [Eu], ao mesmo tempo que prefigura sua destinação alienante" (LACAN, 1998b, p. 98). Há, pois, a simultaneidade da constituição e da perda, "o hiato que, separando-me do exterior, separa-me de mim mesmo" (ARANTES, 2003, p. 56).

\section{A imagem e o desejo}

À alienação primordial que caracteriza a aparição especular de um outro funcionando como Gestalt soma-se que essa imagem é sempre investida de desejo. Nas palavras de Lacan, "à projeção da imagem, sucede constantemente a do desejo. Correlativamente, há re-introjeção da imagem e reintrojeção do desejo. Jogo de báscula, jogo em espelho [...] e ao longo desse ciclo, seus desejos são reintegrados, reassumidos pela criança" (LACAN, 2003b, p. 207). O momento da primeira apreensão especular é também o movimento de "despertar" do desejo, que é, sem dúvida, um desejo por esse outro revelado na introjeção da imagem:

o desejo perde aqui todo o mistério e aparece em plena luz, na superfície plana e brilhante do espelho que representa sua profundeza ilusória. Ele é literalmente achatado nessa experiência que o revela como um puro comportamento de fascínio em relação à imagem, prova que lhe dá logo a forma torneada de uma relação consigo (OLGIVIE, 1991, p. 110).

Destarte, o aspecto jubilatório que marcara o início de nossa observação sobre o estádio do espelho recebe nova luz, pois depreende-se que ele fornece a fatura de certo interesse plenamente investido de desejo que exerce uma função "cativante" em relação ao sujeito.

Ora, se esse traçado permite uma vez mais entrever linhas de afinidade entre a antropologia lacaniana e a kojèveana, o passo seguinte as torna ainda mais aderentes, visto que "o corpus lacaniano superpõe sem cerimônia criança e consciência-de-si" (ARANTES, 2003, p. 58), conjugando o estado "prematuro" ou "pré-corporal" àquele que Kojève denominava o "vazio irreal" do ser "absorvido" no "sentimento de si". Se, para o filósofo russo, é o desejo que promove o rompimento 
da relação de conaturalidade que marca o conhecimento animal, inaugurando o momento em que o homem "se constitui e se revela", ou seja, o momento em que ele pode então dizer "Eu", para Lacan, considerada sua peculiaridade de concepção do eu como corpo próprio, funciona basicamente ${ }^{11}$ a mesma lógica:

o sujeito localiza e reconhece originalmente o desejo por intermédio não só da sua própria imagem, mas também do corpo do seu semelhante. É exatamente aí, neste momento, que se isola, no ser humano, a consciência enquanto consciência de si. É na medida em que é no corpo do outro em que ele reconhece o seu desejo que a troca se faz. É na medida em que seu desejo passou para outro lado, que ele assimila o corpo do outro e se reconhece como corpo" (LACAN, 2003b, pp. 172-173).

O desejo concentra a função antropogênica de levar o homem à consciência-de-si por via do "reconhecimento" de seu desejo no outro. Há um sugestivo imbricamento da temática kojèveana da formação social do Eu através de um processo de reconhecimento entre consciências mediado pelo desejo às paragens do imaginário lacaniano. Nessa direção, bastaria notar o momento no qual "o desejo originário, inconstituído e confuso" que é visto no outro, por meio de um "jogo de báscula em que trocou justamente o seu eu por esse desejo que vê no outro" (Lacan, 2003b, p. 206), é "invertido" ou "alienado" no outro, outro que, por sua vez, o sujeito aprenderá a reconhecer. Esse reconhecimento só é possível porquanto o sujeito carrega consigo a duplicação da imagem própria decorrente de sua identificação através da alteridade num "jogo de báscula" que, por sua vez, duplica também seu desejo num "jogo em espelho". É a essa altura que surge, nas palavras de Lacan, "o tema hegeliano fundamental - o desejo do homem é o desejo do outro" (LACAN, 2003b, p. 172).

\section{Identificação narcísica e agressividade}

Ao caráter dessa alienação do desejo invertido e reconhecido no outro soma-se a compleição eminentemente narcísica do desejo, que faz com que o reconhecimento no outro se transforme num reconhecimento pelo outro, inaugurando a "luta por reconhecimento". No entanto, vejamos antes o que se entende aqui por "narcísico" para que melhor possamos compreender a abordagem da "luta de consciências". Se o desejo, como vimos, é função determinante da interação do sujeito ao seu meio ambiente - dado que surge no bojo da Gestalt de sua primeira identificação - as relações do homem com seu meio ambiente nunca se passarão de modo a tomar os objetos em sua "nudez ontológica", como um "em-si" ou qualquer outra forma de "objetivismo". A realidade específica do homem faz com que ele apreenda essa realidade desde sempre num terreno social mediado pelo desejo, que ocupa, assim, o papel de operador central da sua relação com os objetos. $O$ homem só encontra nos objetos aquilo que o seu desejo ali colocou, o que demonstra que o imaginário é essencialmente narcísico. Mais do que isso, o caráter eminentemente negativo do desejo - "o desejo é essencialmente uma negatividade" (LACAN, 2003b, p. 172) - faz com que o objeto seja "secundário" frente ao desejo. Recordemos que em Kojève o desejo também era tomado como um "nada revelado", um "vazio irreal" precursor de uma "transcendência negativa" por parte do desejo, uma vez que para se

11 Basicamente e não totalmente, pois, como lembra Arantes (2003, p. 50), "Lacan sustenta que é no outro que o sujeito se identifica [...] Kojève não dizia exatamente isso, mas todos estavam convencidos de ter ouvido exatamente isso".

SILVA, Anderson Aparecido Lima da. Kojève, Lacan e a formação do eu. Griot : Revista de Filosofia, Amargosa - BA, v.22 n.1, p..6884, fevereiro, 2022. 
posicionar, para se afirmar em sua determinidade, o sujeito tinha de transcender todo objeto, porto no qual podemos dizer que se ancora também o narcisismo de Lacan.

Contudo, frise-se, esse narcisismo nada tem de solipisismo, já que "Alter e Ipse articulam-se necessariamente na idéia de narcisismo, e a constituição centrípeta do sujeito, através da intervenção da alteridade, é condição da constituição do objeto. É a idéia hegeliana da Anerkennung (reconhecimento intersubjetivo), proposta como condição da recognição do objeto" (PRADO JÚNIOR, 2003, p. 239). Com o narcisismo relaciona-se, consequentemente, a dimensão da alteridade, o que pode ser traduzido dizendo-se que o desejo implica sempre um outro, o desejo é sempre "social", posto que "mediatizado" pelo(s) outro(s). Levado ao extremo das decorrências dessa premissa, Kojève defendia que o desejo que busca um objeto natural só é humano "na medida em que é mediatizado pelo desejo de outrem dirigido ao mesmo objeto". Isto é, o que se deseja do objeto não é exatamente o desejo do objeto por si mesmo mas o alter-desejo "intencionado" a tal objeto. Não se deseja objetos, apenas desejos. Ora, ao analisarmos a trama do ciúme divisaremos de modo mais claro que é precisamente este o ponto de vista de Lacan: a negatividade do desejo, no fundo, não deseja este ou aquele objeto, mas o desejo nele investido, marcando, dessa maneira, a "ligação do eu a situações socialmente elaboradas", conquanto "decididamente faz todo saber humano bascular para a mediatização pelo desejo do outro, constituir seus objetos numa equivalência abstrata" (LACAN, 1998b, p. 101). Essa "polivalência instrumental' dos objetos e sua 'polivalência' simbólica introduz uma certa 'ruptura de nível', um certo desacordo entre homem e natureza, e ao mesmo tempo "extende idefinidamente seu mundo e seu poder" (MÜLLER; WILLIAM, 1985, p. 33). Uma vez mais, é o "desejo antropogênico" que vem efetuar a passagem natureza/cultura.

Disposto esse quadro, passemos à "luta de consciências".

Como vimos, há uma tensão correlativa à estrutura narcísica, isso porque, por um lado, o reconhecimento do Eu e seu desejo somente pode se efetuar através do outro, porém, ao mesmo tempo, a narcísica negatividade do desejo - chamada por Lacan de "negatividade existencial" implica que o eu se posicione para "impor" seu desejo, não só aos objetos mas também ao outro, ressaltando assim "a evidente relação da libido narcísica com a função alienante do [eu]" (LACAN, 1998b, p. 102). Uma vez cruzados narcisismo e alienação, a estrutura mais recorrente é a destruição daquele que é sede da alienação do eu, o seu rival portanto, despertando como resultado a agressividade inerente às relações humanas, que não só "determina o despertar de seu desejo pelo objeto do desejo do outro" (LACAN, 1998d, p. 116), mas insere efetivamente o indivíduo numa "trama sócio-simbólica" na qual "o próprio desejo do homem constitui-se sob o signo da mediação: ele é o desejo de fazer seu próprio desejo reconhecido. Ele tem por objeto um desejo, o do outro, no sentido de que o homem não tem objeto que se constitua para seu desejo sem alguma mediação" (LACAN, 1998c, p. 183).

Notemos a aproximação quase literal deste trecho com aquele no qual Kojève expunha a armação do campo da "luta por reconhecimento":

desejar o desejo do outro é, em última análise, desejar o valor que eu sou ou que represento seja o valor desejado por esse outro: quero que ele reconheça meu valor como seu valor, quero que me reconheça como um valor autônomo. Isto é, todo desejo humano, antropogênico, gerador da consciência-de-si é, pois, função do desejo de reconhecimento" (KOJÈVE, 2002, p. 14). 
O "desejo de reconhecimento", por sua vez, só pode se resolver numa "luta de puro prestígio". Luta de "puro prestígio" que, como sabemos, dará ocasião à "alienação" de uma das consciências em combate, que passa a reconhecer sem ser reconhecida, qual seja, o escravo, que é sempre escravo de um senhor. Não é difícil notar, então, a facilidade com a qual Lacan maneja e conjuga o desejo narcísico (imposição de um valor, em Kojève), reconhecimento, alienação e agressividade (ou luta).

Estando as três instâncias - desejo narcísico, reconhecimento e alienação - desde sempre juntas e implicando-se mutuamente, o resultado será a rivalidade ou concorrência como um fator intrínseco a todo contato inter-humano: como dirá Lacan, "a agressividade se manifesta em uma experiência que é subjetiva por sua constituição mesma" (LACAN, 1998d, p. 102). Atentemos que "esta proposição quer dizer que, não só a experiência agressiva se constitui como subjetiva, mas também, como já foi repisado tantas vezes, que a experiência que constitui o sujeito dá-se sobre o signo da agressividade" (SIMANKE, 2002, p. 332).

Desse modo, "cada vez que o sujeito se apreende como forma e como eu, cada vez que se constitui no seu estatuto, na sua estatura, na sua estática, o seu desejo se projeta para fora", e uma vez que "o desejo só existe no plano especular, projetado, alienado no outro, a tensão que ele provoca é desprovida de saída", desprovida de saída porque "o desejo do sujeito só pode, nessa relação, se confirmar através de uma concorrência, de uma rivalidade absoluta com o outro", sendo o motivo pelo qual a "cada vez que nos aproximamos, num sujeito, dessa alienação primordial, se engendra a mais radical agressividade - o desejo de desaparecimento do outro enquanto suporte do desejo do sujeito" (LACAN, 2003b, pp. 197-198). Essa rivalidade originária estende-se também às relações de objeto:

\begin{abstract}
"o objeto humano [uma vez que difere fundamentalmente do objeto animal, recordemos] é originariamente mediatizado pela via da rivalidade, pela exacerbação da relação ao rival, pela relação de prestígio e de prestância. Já é uma relação da ordem da alienação porque é primeiro no rival que o sujeito se apreende como eu. A primeira noção da totalidade do corpo como inefável, vivido, o primeiro arroubo do apetite e do desejo passa no sujeito humano pela mediação de uma forma que primeiro ele vê projetada, exterior a ele, e isso, primeiro, no seu próprio reflexo" (LACAN, 1998d, p. 112).
\end{abstract}

Nos dois casos, a agressividade surge, por fim, como "a tendência correlativa a um modo de identificação a que chamamos narcísico, e que determina a estrutura formal do eu do homem e do registro de entidades característico de seu mundo" (LACAN, 1998d, p. 112). Nesse sentido, a exposição de Lacan vai ao encontro de que "é na luta mortal de puro prestígio que o homem se faz reconhecer pelo homem" (LACAN, 1998e, p. 149). E se posteriormente Lacan enxergará na insistência cega dessa rivalidade por si só - enquanto não mediada pelo reconhecimento da linguagem, introduzida por via do âmbito do simbólico ${ }^{12}$ - o "impasse" de uma "relação perversa", devemos, por ora, apenas nos ater à observação de que a agressividade não é sinônimo e nem mesmo pressupõe agressão tout court, ponto indispensável para que possamos compreender que a "luta mortal" do reconhecimento não deve ser entendida em seu sentido literal, pois "a agressão nada tem

\footnotetext{
12 "Graças a Deus, o sujeito está no mundo do símbolo, quer dizer, no mundo de outros que falam. É por isso que seu desejo é suscetível da mediação do reconhecimento. Sem o que toda função humana só poderia esgotar-se na aspiração indefinida da destruição do outro como tal" (Lacan, 2003b, p. 198).
}

SILVA, Anderson Aparecido Lima da. Kojève, Lacan e a formação do eu. Griot : Revista de Filosofia, Amargosa - BA, v.22 n.1, p..6884, fevereiro, 2022. 
a ver com a realidade vital, é um ato existencial ligado a uma relação imaginária" (LACAN, 2003b, p. 205. Grifo nosso).

Posto isso, não se deve perder de vista que "esse desenvolvimento é vivido como uma dialética temporal que projeta decisivamente na história a formação do indivíduo" (LACAN, 1998b, p. 100). Trata-se de um verdadeiro "drama" conflitual no qual a temática da "história dos desejos desejados" vem à tona com toda sua força, isso porque a totalidade desse quadro se dá no decorrer do processo de sociabilização do desejo do sujeito, que vê nas imagens o drama de seus desejos. Nesse contexto, para ressaltar o caráter dramático da imagem, Lacan resgata o conceito de imago, imagem investida de desejo que marcará a trajetória de relações da inserção do sujeito na trama sócio-simbólica do núcleo social, ou ainda, se quisermos ficar com a precisa definição de Richard Simanke (2002, p. 161), "precipitados identificatórios das relações sócio-vitais que constituem os complexos".

$\mathrm{O}$ "drama do ciúme primordial" enfatiza esse processo de maneira exemplar, pois se trata de uma situação concreta cuja análise, ainda que superficial, nos permite cruzar a vertente da constituição da realidade, através das imagens dos objetos, com a da constituição do sujeito, através das identificações com as quais ele se reconhece, ou seja, relacionar internamente o triângulo formado pelo eu, pelo outro e pelo objeto, e tudo isso de modo a resgatar o caráter imaginário e não-vital da agressividade. Vejamos como, ao abordar o tema do ciúme, mais especificamente do ciúme infantil, em seu texto "os complexos familiares na formação do indivíduo" (1936), Lacan inicia citando uma passagem das Confissões (I, VII), de Santo Agostinho: "vi com meus próprios olhos e observei bem um menino tomado de ciúme: ele ainda não falava, mas não conseguia desviar os olhos, sem empalidecer, do amargo espetáculo de seu irmão de leite". Segundo o psicanalista, o que se passa nessa cena é desenrolar de uma "rivalidade objetivamente definível", determinada pela "intrusão" do irmão mais novo.

O que mobiliza o ciúme em relação à imagem do irmão não é uma disputa vital, não é uma disputa pelo alimento, por exemplo, porém, a percepção de que a imagem do irmão ocupa o lugar daquilo que o sujeito deseja e do qual é excluído, qual seja, o desejo da mãe. Dito de outro modo,

o drama do ciúme traduz-se justamente na disputa por um objeto, alvo de desejo somente por ser desejado pelo outro. É por isso, aliás, que a rivalidade em torno do alimento (o leite materno) pode ser despojada de seu caráter natural. Vê-se, por aí, que é essa relação eu/outro originária que desencadeia o processo de construção da realidade humana - o Unwelt do homem - como uma edificação imaginária, imaginário este profundamente enraizado no mundo da vida, que ele nega e supera, no mais puro espírito da Aufhebung (SIMANKE, 2002, p. 269).

Mais uma vez, a leitura de Kojève insinua a direção desta "antropologização" - ou "hominização", como quer Lacan - que encontra no desejo seu operador essencial. Se o filósofo divisava na "dialética do Senhor e do Escravo" o centro da fenomenologia das relações históricohumanas, o psicanalista identificará no "complexo de intrusão" - cerne do reconhecimento/rivalidade das relações humanas - o "complexo nuclear" do desenvolvimento e "arquétipo dos sentimentos sociais" (LACAN, 2003, p. 50). Não é difícil compreender o porquê, pois ao colocar a "agressividade original" num terreno notadamente antropológico, isto é, ao concentrar a luta no terreno do imaginário e não do vital, Lacan encontra mais do que uma maneira engenhosa de contornar o "biologismo" de Freud expresso em sua "pulsão de morte": uma vez que todo esse processo é marcado pelo fato de que os objetos são sempre socialmente representativos, o psicanalista francês se vê na

SILVA, Anderson Aparecido Lima da. Kojève, Lacan e a formação do eu. Griot : Revista de Filosofia, Amargosa - BA, v.22 n.1, p..6884, fevereiro, 2022. 
possibilidade de reformular o conceito de "narcisismo": não há necessidade de buscar causas psicofisiológicas ou de recorrer às vicissitudes internas da libido, na verdade, é na imago, "objeto próprio da psicologia", que devemos buscar a "forma de causalidade que é a própria causalidade psíquica" (LACAN, 1998c, p. 189).

\section{Conclusão}

Desse modo, o "estádio do espelho" completa seu objetivo de prover a Lacan uma "guinada antropológica" que não apenas lhe permite substituir o determinismo próprio à causalidade psíquica da esfera do orgânico/mental ao mental/social como também o capacita a elaborar uma "antropogênese" no sentido mais vasto que este termo pode supor, passando tanto pela constituição "ontológica" do sujeito quanto por sua gênese numa situação social. Seria exagerado, se não despropositado e de pouco interesse, creditar integralmente a Kojève a originalidade, os usos e as implicações filosóficas e psicanalíticas desenvolvidas por Lacan. Por outro lado, seria injusto menosprezar os efeitos da criatividade da leitura de Kojève na construção de uma teoria do imaginário respaldada na desnaturalização do desejo, na insistência de seu caráter antropogênico, de sua mediação pelo desejo de um outro, na implicação entre desejo e reconhecimento, em sua trama passional e social de rivalidade e concorrência como "ato existencial".

Mais do que uma mera interlocução episódica, o encontro entre Kojève e Lacan marca um dos capítulos essenciais de uma encruzilhada complexa na qual o pensamento contemporâneo - plasmado nas linhas da fenomenologia, do marxismo e do existencialismo - retomou a inspiração hegeliana na tentativa de compreensão de questões fundamentais do século XX, buscando colocar a filosofia, a história, a psicologia, à altura da existência humana em sua "concretude". Uma dívida que mesmo alguém insuspeito de hegelianismo assim sintetizava no início dos anos 1970:

\footnotetext{
escapar realmente de Hegel supõe apreciar exatamente o quanto custa separar-se dele; supõe saber até onde Hegel, insidiosamente, talvez, aproximou-se de nós; supõe saber, naquilo que nos permite pensar contra Hegel, o que ainda é hegeliano; e medir em que nosso recurso contra ele é ainda, talvez, um ardil que ele nos opõe, ao termo do qual nos espera, imóvel e em outro lugar (FOUCAULT, 1996, p.72-73.
}

Num momento em que o futuro da psicanálise parece colocado em xeque pela hipermedicalização e pelos teóricos do cérebro-máquina dispostos a dissociar o orgânico do cultural e do psíquico (ROUDINESCO, 2000), retornar às aspirações que animaram esse momento do pensamento e da prática de Jacques Lacan talvez possa nos auxiliar a formular a questão do quanto custa nos livrarmos da Psicanálise e de seu diálogo com a Filosofia. E o quão esse diálogo é ainda capaz de nos fazer aproximarmo-nos de nós, mesmo diante daquilo que, hoje, lhe parece contraditório. Diante desse quadro, caberia questionar em que medida, mais do que ter se servido de Hegel, Lacan não teria emulado como poucos essa peculiar virtude do filósofo, essa astúcia que faz com que a cada vez que procuramos "escapar" de Lacan, encontramo-lo mais à frente, também a nos esperar em outro lugar. 


\section{Referências}

ARANTES, Paulo Eduardo. "Um Hegel errado mas vivo: notícia sobre o seminário de Kojève". In: Formação e Desconstrução: uma visita ao Museu da Ideologia Francesa. SP, Editora 34, 2021, pp. 223240.

ARANTES, Paulo Eduardo. "Hegel no espelho do Dr. Lacan". In: SAFATLE, V. (org.). Um limite tenso: Lacan entre a filosofia e a psicanálise. SP, Ed. Unesp, 2003.

AUFFRET, Dominique. Alexandre Kojève. Paris, Grasset, 1990.

DESCOMBES, Vincent. Le même et l'autre - quarante-cinq ans de philosophie française (1933 - 1978). Paris, Les Éditions de Minuit, 1979.

FOUCAULT, Michel. A ordem do discurso. Aula inaugural no Collège de France pronunciada em 2 de dezembro de 1970. Trad. de Laura Fraga de Almeida Sampaio. SP, Loyola, 1996.

JARCZYK, Gwendoline; LABARRIÈRE, Jean-Pierre. De Kojève à Hegel - Cent cinquante ans de pensée hégélienne en France. Paris, Albin Michel, 1996.

KOJÈVE, Alexandre. Introduction à la lecture de Hegel : leçons sur la Phénoménologie de l'esprit, proféssées de 1933 à 1939 à l'École des Hautes Études, réunis et publiées par Raymond Queneau. Paris, Gallimard, 1947.

KOJÈVE, Alexandre. Introdução à leitura de Hegel. Trad. Estela dos Santos Abreu. RJ, EdUerj/Contraponto, 2002.

LACAN, Jacques. De la psychose paranoïaque dans ses rapports avec la personnalité. Paris, Le François, 1932.

LACAN, Jacques. Da Psicose paranoica em suas relações com a personalidade, seguido de primeiros escritos sobre a paranoia. Trad. A. Menezes, M. A. Coutinho Jorge, Potiguara M. da Silveira. RJ, Forense Universitária, 1987.

LACAN, Jacques. Écrits. Paris, Éditions du Seuil, 1966.

LACAN, Jacques. "Para além do "princípio de realidade". In: LACAN, J. Escritos. Trad. Inês OsckiDepré. RJ, Jorge Zahar Editor, 1998a.

LACAN, Jacques. "O estádio do espelho como formador da função do eu". In: LACAN, J. Escritos. Trad. Inês Oscki-Depré. RJ, Jorge Zahar Editor, 1998 b.

LACAN, Jacques. "Formulações sobre a causalidade psíquica". In: LACAN, J. Escritos. Trad. Inês Oscki-Depré. RJ, Jorge Zahar Editor, 1998c.

LACAN, Jacques. “A agressividade em psicanálise”. In: LACAN, J. Escritos. Trad. Inês Oscki-Depré. RJ, Jorge Zahar Editor, 1998d.

LACAN, Jacques. "Introdução teórica às funções da psicanálise em criminologia". LAGAN, J. Escritos. Trad. Inês Oscki-Depré. RJ, Jorge Zahar Editor, 1998e.

LACAN, Jacques. "Os complexos familiares na formação do indivíduo". In: Outros Escritos. Trad. Vera Ribeiro. RJ, Jorge Zahar Editor, 2003.

LACAN, Jacques. O Seminário, Livro 1- Os escritos técnicos de Freud (1953 - 1954). Trad. Betty Milan. RJ, Jorge Zahar Editor, 2003b.

MARCOS, Jean-Pierre. "Subversão da imagem: contribuição a uma leitura de 'Para além do princípio de realidade" (1936)". In: SAFATLE, V. (Org.). Um limite tenso: Lacan entre a filosofia e a psicanálise. SP, Ed. Unesp, 2003.

MILLER, Jacques-Alain. Percurso de Lacan: uma introdução. RJ, Jorge Zahar Editor, 1999.

SILVA, Anderson Aparecido Lima da. Kojève, Lacan e a formação do eu. Griot : Revista de Filosofia, Amargosa - BA, v.22 n.1, p..6884, fevereiro, 2022. 
MÜLLER, John.; WILLIAM, Richardson. Lacan and Language - A reader's guide to "Écrits", New York, International Universities Press, 1985.

OLGIVIE, Bertrand. Lacan, a formação do conceito de sujeito (1939 - 1949), RJ, Jorge Zahar Editor, 1991.

POLITIZER, Georges. Critique des fondements de la psychologie: La psychologie et la psychanalyse. [1928] Paris, PUF, 2003.

PRADO JÚNIOR, Bento. "Lacan: biologia e narcisismo ou a costura entre o real e o imaginário". In: SAFATLE, Vladimir. (Org.). Um limite tenso: Lacan entre a filosofia e a psicanálise. SP, Ed. Unesp, 2003.

ROUDINESCO, Élisabeth. Por que a psicanálise? Trad. de Vera Ribeiro. SP, Zahar, 2000.

SAFATLE, Vladimir. A Paixão do Negativo-Lacan e a dialética, SP, Ed. Unesp, 2006.

SAFATLE, Vladimir $O$ amor pela superfície: Jacques Lacan e o aparecimento do sujeito descentrado. SP, Dissertação de mestrado. Departamento de Filosofia, Universidade de São Paulo, 1997.

SARTRE, Jean-Paul. Situações I. Trad. Cristina Prado. SP, Cosac\&Naify, 2005.

SIMANKE, Richard. Metapsicologia Lacaniana - Os anos de formação, SP, Discurso Editorial, 2002.

Autor(a) para correspondência / Corresponding author: Anderson Aparecido Lima da Silva. anderson.usp@outlook.com 